\title{
2-(Substituted phenyl)-3,4-dihydroisoquinolin-2-iums as Novel Antifungal Lead Compounds: Biological Evaluation and Structure-Activity Relationships
}

\author{
Zhe Hou ${ }^{1, \dagger}$, Rui Yang ${ }^{1, \dagger}$, Cen Zhang ${ }^{1}$, Li-Fei Zhu ${ }^{1}$, Fang Miao ${ }^{2}$, Xin-Juan Yang ${ }^{1, *}$ and Le Zhou ${ }^{1, *}$ \\ 1 College of Science, Northwest A\&F University, Yangling 712100, Shaanxi, China; \\ E-Mails: houzhe561@sina.com (Z.H.); yrer01018@126.com (R.Y.); z84934067@126.com (C.Z.); \\ zhao_fx0309@163.com (L.-F.Z.) \\ 2 College of Life Science, Northwest A\&F University, Yangling 712100, Shaanxi, China; \\ E-Mail: miaofangmf@163.com
}

$\dagger$ These authors contributed equally to this work.

* Authors to whom correspondence should be addressed; E-Mails: yxjsn2@163.com (X.-J.Y.); zhoulechem@nwsuaf.edu.cn (L.Z.); Tel./Fax: +86-29-8709-2226 (L.Z.\& X.-J.Y.).

Received: 5 July 2013; in revised form: 18 July 2013 / Accepted: 22 August 2013 /

Published: 29 August 2013

\begin{abstract}
The title compounds are a class of structurally simple analogues of quaternary benzo[c]phenanthridine alkaloids (QBAs). In order to develop novel QBA-like antifungal drugs, in this study, 24 of the title compounds with various substituents on the $N$-phenyl ring were evaluated for bioactivity against seven phytopathogenic fungi using the mycelial growth rate method and their SAR discussed. Almost all the compounds showed definite activities in vitro against each of the test fungi at $50 \mu \mathrm{g} / \mathrm{mL}$ and a broad antifungal spectrum. In most cases, the mono-halogenated compounds 2-12 exhibited excellent activities superior to the QBAs sanguinarine and chelerythrine. Compound $\mathbf{8}$ possessed the strongest activities on each of the fungi with $\mathrm{EC}_{50}$ values of $8.88-19.88 \mu \mathrm{g} / \mathrm{mL}$ and a significant concentration-dependent relationship. The SAR is as follows: the $N$-phenyl group is a high sensitive structural moiety for the activity and the characteristics and position of substituents intensively influence the activity. Generally, electron-withdrawing substituents remarkably enhance the activity while electron-donating substituents cause a decrease of the activity. In most cases, ortha- and para-halogenated isomers were more active than the corresponding $m$-halogenated isomers. Thus, the title compounds emerged as promising lead compounds for the development of novel biomimetic antifungal
\end{abstract}


agrochemicals. Compounds $\mathbf{8}$ and $\mathbf{2}$ should have great potential as new broad spectrum antifungal agents for plant protection.

Keywords: 2-aryl-3,4-dihydroisoquinolin-2-ium; antifungal activity; phytopathogenic fungi; structure-activity relationship; sanguinarine; chelerythrine

\section{Introduction}

Fungal plant diseases are one of the important concerns to agricultural production and food safety worldwide [1]. Phytopathogenic fungi are able to infect any tissue at any stage of plant growth, and result in severe yield losses and the quality decrease of agricultural products. In addition, many of the phytofungal pathogens may produce mycotoxins harmful to animal and human health [2]. Therefore, various plant fungicides are extensively used in current agriculture. However, many of the currently used antifungal agents have several shortcomings, such as affecting human health, environmental pollution and development of pathogen resistance [3]. Thus, the worsening problems of phytofungal disease control urgently necessitate the discovery and development of new antifungal agents for plant protection.

In the past decades, natural product-based antimicrobial agents had attracted a lot of attention from researchers owing to the fact they are perceived to have less environmental toxicity and lower mammalian toxicity [4]. Although most natural antifungal compounds are not suitable for direct or extensive application as agricultural fungicides because of their lower activity than that of artificial antimicrobial agents, limited sources or higher cost, they have been considered as ideal leads or model compounds for the development of new environmentally acceptable antimicrobial agents.

Quaternary benzo[c]phenanthridine alkaloids (QBAs) are a relatively small but important class of natural isoquinolines $[5,6]$. Among them, sanguinarine (SA) and chelerythrine (CH) (Figure 1) are the most common. QBAs had been proven to have low toxicity to mammals [7-9] and extensive pharmacological activities such as antitumor [10], antimicrobial [11,12], anti-inflammatory [7], anti-HIV [13], anti-angiogenesis [14], anti-acetylcholinesterase [15] and antiparasitic actions against Trichodina sp. [16], Dactylogyrus intermedius [17], malaria [18] and Psoroptes cuniculi [6]. QBAs extract from plants have been used in toothpastes and mouthwashes as antiplaque agents, a veterinary preparation for mastoiditis in cows and an additive to animal feeds [8]. Our previous studies also demonstrated that sanguinarine and chelerythrine possessed excellent bioactivities against phytopathogenic fungi [19]. Particularly, it was worth mentioning that the iminium moiety $\left(\mathrm{C}=\mathrm{N}^{+}\right)$in SA and CH had been proven to be the key structural moiety for their antimicrobial activity [12,19] and acaricidal activity [6]. The similar case was also found for their anti-tumor activity [20].

In order to develop more potent isoquinoline drugs, we designed a class of structurally simple QBAs-like compounds, i.e., 2-aryl-3,4-dihydroisoquinolin-2-iums (1-24, Figure 1), based on a structural biomimetic strategy. Like QBAs, the compounds 1-24 possess an isoquinoline framework containing an iminium moiety $\left(\mathrm{C}=\mathrm{N}^{+}\right)$. Besides, the compounds have approximate equal molecular length to QBAs. We expected that the structural similarity between the designed compounds and their model compounds can lead to discovery of new compounds with higher bioactivity than the model 
compounds. It should be noted that unlike the complete planarity of QBAs, the compounds 1-24 have different stereo structures from QBAs due to the existence of a dihedral angle between two phenyl rings. The changeable dihedral angle endows the molecules with flexibility and was expected to make the molecules better match the environment of the binding site of their biotarget and display higher bioactivity.

The title compounds may be easily prepared from commercially available isochroman according to our previously reported method [21]. The reaction of isochroman with 57\% hydroiodic acid under reflux yielded 1-(2-iodoethyl)-2-(iodomethyl)benzene in 96\% yield. A solution of the resultant diiodide and aniline or substituted aniline in water was refluxed in the presence of sodium dodecyl sulfonate (SDS) as phase-transfer catalyst to afford the corresponding 2-aryl-1,2,3,4-tetrahydroisoquinoline in $86 \%-94 \%$ yield. Finally, the 2-aryl-1,2,3,4-tetrahydroisoquinolines were selectively oxidized with DDQ (2,3-dichloro-5,6-dicyano-p-benzoquinone) or $\mathrm{CuCl}_{2} \cdot 2 \mathrm{H}_{2} \mathrm{O}$ followed by treatment of hydrobromic acid to provide the title compounds as solids in $40 \%-99 \%$ yield.

Figure 1. Structures of the target compounds and their model compounds.

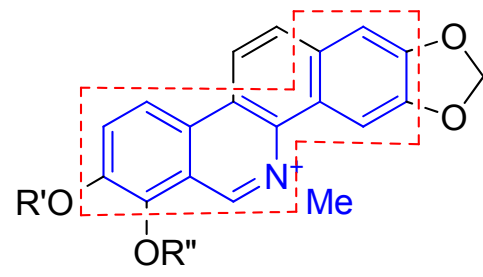

Sanguinarine (SA): $\mathrm{R}^{\prime}+\mathrm{R}^{\prime \prime}=\mathrm{CH}_{2}$ Chelerythrine $(\mathbf{C H}): \mathrm{R}^{\prime}=\mathrm{R}^{\prime \prime}=\mathrm{Me}$

(Natural model compounds)
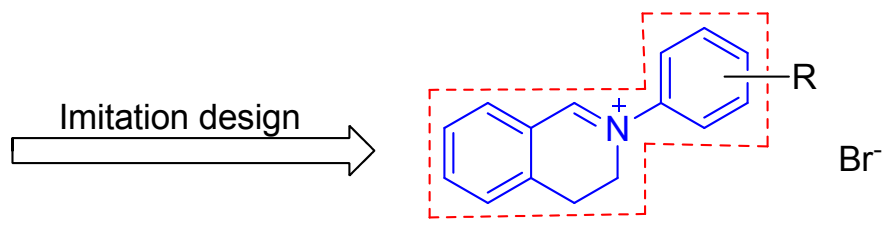

Target compounds (1-24)

As a part of our ongoing program for the development of QBAs-like isoquinoline drugs, we report herein the evaluation of the antifungal activity of compounds 1-24 against various plant pathogenic fungi and the establishment of their structure-activity relationships. To our knowledge, there has been no information on the antifungal activity of the title compounds in the literature until now.

\section{Results and Discussion}

\subsection{Screening of Antifungal Activity in Vitro}

Compounds 1-24 were obtained by chemical synthesis according to our previous method [21] and their structures and substituent patterns are shown in Figure 1 and Table 1. According to the mycelial linear growth rate method [19], 1-24 were screened for antifungal activities in vitro against seven phytopathogenic fungi (Alternaria alternate, Curvularia lunata, Pyricularia oryza, Fusarium solani, Valsa mali, Fusarium oxysporum sp. niveum and Fusarium oxysporum f. sp. vasinfectum.) at $50 \mu \mathrm{g} / \mathrm{mL}$. SA iodide and CH iodide as model compounds, and triabendazole (TBZ, $\geq 99 \%$ ), a commercial fungicide standard, were used as positive controls. Mean inhibition rates of all the test compounds against the same fungus were pairwise compared by Duncan's multiple test. The results are listed in Table 1. 
Table 1. Substituent patterns and antifungal activities of compounds at $50 \mu \mathrm{g} / \mathrm{mL}$ (72 h). *

\begin{tabular}{|c|c|c|c|c|c|c|c|c|}
\hline \multicolumn{2}{|c|}{ Compound } & \multicolumn{7}{|c|}{ Linear growth inhibitory rates (means, \%) $* *$} \\
\hline No. & $\mathrm{R}$ & A.A. & C.L. & P.O. & F.S. & V.M. & F.O.N. & F.O.V. \\
\hline 1 & $\mathrm{H}$ & $56.8 \mathrm{~h}$ & $76.7 \mathrm{ef}$ & $50.6 \mathrm{hi}$ & $23.5 \mathrm{k}$ & 32.41 & $50.8 \mathrm{~h}$ & $25.6 \mathrm{~m}$ \\
\hline 2 & $o-\mathrm{F}$ & $78.4 \mathrm{~b}$ & $95.1 \mathrm{a}$ & $69.9 \mathrm{~b}$ & $85.4 \mathrm{~b}$ & $80.8 \mathrm{bc}$ & $80.1 \mathrm{c}$ & $71.3 \mathrm{c}$ \\
\hline 3 & $m$-F & $66.4 \mathrm{def}$ & 86.9 bcd & $62.2 \mathrm{cdef}$ & 48.5 ghij & $54.2 \mathrm{i}$ & $44.1 \mathrm{i}$ & $43.1 \mathrm{~h}$ \\
\hline 4 & $p-\mathrm{F}$ & $78.4 \mathrm{~b}$ & $73.4 \mathrm{fg}$ & 62.2 cdef & $59.7 \mathrm{def}$ & $66.4 \mathrm{~g}$ & $71.1 \mathrm{de}$ & $59.5 \mathrm{e}$ \\
\hline 5 & $o-\mathrm{Cl}$ & $84.1 \mathrm{a}$ & $84.1 \mathrm{~cd}$ & $67.9 \mathrm{bc}$ & $59.2 \mathrm{def}$ & 72.9 ef & $74.0 \mathrm{f}$ & $55.8 \mathrm{f}$ \\
\hline 6 & $m-\mathrm{Cl}$ & $68.3 \mathrm{~d}$ & $84.5 \mathrm{~cd}$ & $60.9 \mathrm{def}$ & $62.1 \mathrm{de}$ & $72.1 \mathrm{ef}$ & $36.6 \mathrm{j}$ & $34.9 \mathrm{ij}$ \\
\hline 7 & $p-\mathrm{Cl}$ & $78.4 \mathrm{~b}$ & $89.0 \mathrm{bc}$ & 64.1 bcde & 55.8 defgh & $61.2 \mathrm{~g}$ & $74.0 \mathrm{f}$ & $65.1 \mathrm{~d}$ \\
\hline 8 & $o-\mathrm{Br}$ & $78.1 \mathrm{~b}$ & $92.0 \mathrm{ab}$ & $82.3 \mathrm{a}$ & $93.9 \mathrm{a}$ & $71.7 \mathrm{ef}$ & $91.7 \mathrm{~b}$ & $74.6 \mathrm{~b}$ \\
\hline 9 & $p-\mathrm{Br}$ & $72.1 \mathrm{c}$ & $69.4 \mathrm{~g}$ & $62.8 \mathrm{cde}$ & 49.0 ghij & $55.5 \mathrm{i}$ & $65.9 \mathrm{f}$ & $61.5 \mathrm{e}$ \\
\hline 10 & $o-\mathrm{I}$ & $65.9 \mathrm{def}$ & $81.6 \mathrm{de}$ & $60.3 \mathrm{def}$ & 55.3 defghi & $70.8 \mathrm{f}$ & $67.3 \mathrm{ef}$ & $52.8 \mathrm{f}$ \\
\hline 11 & $m-\mathrm{I}$ & $64.2 \mathrm{f}$ & $84.9 \mathrm{~cd}$ & $59.0 \mathrm{defg}$ & 54.3 efghi & $53.3 \mathrm{i}$ & $28.5 \mathrm{k}$ & $25.6 \mathrm{~m}$ \\
\hline 12 & $p$-I & $60.6 \mathrm{~g}$ & $73.4 \mathrm{fg}$ & $53.8 \mathrm{gh}$ & $47.0 \mathrm{ij}$ & $77.3 \mathrm{~cd}$ & $44.1 \mathrm{i}$ & $43.6 \mathrm{~h}$ \\
\hline 13 & $o-\mathrm{CF}_{3}$ & $64.0 \mathrm{f}$ & $73.9 \mathrm{fg}$ & $65.4 \mathrm{bcd}$ & 53.8 efghi & $55.9 \mathrm{i}$ & $48.4 \mathrm{hi}$ & $48.2 \mathrm{~g}$ \\
\hline 14 & $m-\mathrm{CF}_{3}$ & $64.9 \mathrm{ef}$ & $86.1 \mathrm{bcd}$ & $63.5 \mathrm{cde}$ & 47.5 hij & $47.2 \mathrm{j}$ & $35.1 \mathrm{j}$ & $31.3 \mathrm{kl}$ \\
\hline 15 & $p-\mathrm{CF}_{3}$ & $67.8 \mathrm{de}$ & $87.7 \mathrm{bcd}$ & $58.3 \mathrm{efg}$ & $44.6 \mathrm{j}$ & $38.5 \mathrm{k}$ & $36.1 \mathrm{j}$ & $33.8 \mathrm{jk}$ \\
\hline 16 & $o-\mathrm{NO}_{2}$ & $11.1 \mathrm{~m}$ & 4.01 & $12.8 \mathrm{n}$ & $-12.2 \mathrm{n}$ & $2.7 \mathrm{op}$ & $5.3 \mathrm{~m}$ & $8.2 \mathrm{o}$ \\
\hline 17 & $m-\mathrm{NO}_{2}$ & $73.1 \mathrm{c}$ & $73.9 \mathrm{fg}$ & $70.4 \mathrm{~b}$ & $56.81 \mathrm{defg}$ & $47.2 \mathrm{j}$ & $56.9 \mathrm{~g}$ & $52.8 \mathrm{f}$ \\
\hline 18 & $p-\mathrm{NO}_{2}$ & $63.5 \mathrm{f}$ & $60.8 \mathrm{~h}$ & $62.2 \mathrm{cdef}$ & $58.7 \mathrm{def}$ & $82.3 \mathrm{ab}$ & $36.1 \mathrm{j}$ & $37.9 \mathrm{i}$ \\
\hline 19 & $o-\mathrm{Me}$ & $51.0 \mathrm{i}$ & $58.7 \mathrm{ghi}$ & 32.71 & $-0.6 \mathrm{~m}$ & $2.3 \mathrm{p}$ & 13.81 & $10.8 \mathrm{o}$ \\
\hline 20 & $m-\mathrm{Me}$ & $11.6 \mathrm{~m}$ & $41.6 \mathrm{k}$ & $19.2 \mathrm{~m}$ & $2.6 \mathrm{~m}$ & $11.6 \mathrm{n}$ & $8.1 \mathrm{~m}$ & $11.3 \mathrm{o}$ \\
\hline 21 & $p$-Me & $60.1 \mathrm{~g}$ & $57.1 \mathrm{ghi}$ & $35.3 \mathrm{kl}$ & 13.51 & 6.60 & $33.2 \mathrm{j}$ & $21.0 \mathrm{n}$ \\
\hline 22 & $o-\mathrm{OH}$ & $47.2 \mathrm{k}$ & $53.8 \mathrm{ij}$ & $44.9 \mathrm{ij}$ & 53.4 fghi & $11.0 \mathrm{n}$ & $25.2 \mathrm{k}$ & $20.0 \mathrm{n}$ \\
\hline 23 & $p-\mathrm{OH}$ & $58.2 \mathrm{gh}$ & $87.7 \mathrm{~b} \mathrm{~cd}$ & $55.8 \mathrm{fgh}$ & $73.3 \mathrm{c}$ & $76.0 \mathrm{de}$ & $35.1 \mathrm{j}$ & $30.8 \mathrm{kl}$ \\
\hline 24 & $p$-OMe & $55.8 \mathrm{~h}$ & $57.5 \mathrm{hi}$ & $46.8 \mathrm{i}$ & $22.7 \mathrm{k}$ & $25.0 \mathrm{~m}$ & $36.6 \mathrm{j}$ & 29.71 \\
\hline $\mathbf{S A}$ & - & $47.7 \mathrm{jk}$ & $58.7 \mathrm{hi}$ & $40.7 \mathrm{jk}$ & $56.4 \mathrm{defg}$ & $69.1 \mathrm{fg}$ & $50.5 \mathrm{~h}$ & $59.7 \mathrm{e}$ \\
\hline $\mathbf{C H}$ & - & $50.3 \mathrm{ij}$ & $48.7 \mathrm{j}$ & $50.1 \mathrm{hi}$ & $63.5 \mathrm{~d}$ & $57.1 \mathrm{i}$ & $63.2 \mathrm{f}$ & $47.6 \mathrm{~g}$ \\
\hline TBZ & - & 16.41 & 9.31 & $6.4 \mathrm{o}$ & $81.5 \mathrm{~b}$ & $86.0 \mathrm{a}$ & $100.0 \mathrm{a}$ & $100.0 \mathrm{a}$ \\
\hline
\end{tabular}

* A.A., Alternaria alternate; C.L., Curvularia lunata; P.O., Pyricularia oryza; F.S., Fusarium solani; V.M., Valsa mali; F.O.N., Fusarium oxysporum sp. niveum; F.O.V., Fusarium oxysporum f. sp. vasinfectum. ** The differences between data with the different lowercase letters within a column are significant for the same tested fungus $(p<0.05)$.

The results in Table 1 show that almost all the target compounds 1-24 displayed activities in varying degrees against each of the test fungi at $50 \mu \mathrm{g} / \mathrm{mL}$, indicating that the compounds had a wide antifungal spectrum similar to that of SA and $\mathbf{C H}$. For every one of the fungi, all or some of the compounds were found to be more active than SA, CH and/or TBZ $(p<0.05)$. For the fungi $A$. alternate, $C$. lunata and $P$. oryza, all or most of the compounds were more active than $\mathbf{S A}, \mathbf{C H}$ and/or TBZ $(p<0.05)$. Among them, 2, 4, 5, 7 and $\mathbf{8}$ showed the greatest or greater inhibition rates (78.4\%, 78.4\%, 84.1\%, 78.4\% and 78.1\%) on A. alternate, 2, 3, 7, 8, 14, 15 and 23 displayed the strongest or stronger activities with inhibition rates of $95.1 \%, 86.9 \%, 89.0 \%, 92.0 \%, 86.1 \%, 87.7 \%$ and $87.7 \%$ on $C$. lunata, and 8 exhibited the best activity $(82.3 \%)$ on $P$. oryza, followed by $\mathbf{2}(69.9 \%)$, 5 (67.9\%), 7 (64.1\%), 13 (65.4\%) and 17 (70.4\%). 
For each of the fungi $F$., V. mali, solani, $F$. oxysporum sp. niveum and $F$. oxysporum f. sp. vasinfectum, some of the compounds showed higher or equal activity to that of SA, CH or TBZ. For F. solani, 15 of the compounds showed the same or higher activities (48.5-93.9\%) than that (56.4\%) of SA while 10 compounds gave the same or higher activities $(55.3-93.9 \%)$ than that (63.5\%) of $\mathbf{C H}$ ( $p>0.05)$. Among them, 8 and 2 gave the strongest activity $(93.9 \%, 85.4 \%)$ over or equal to that $(81.5 \%)$ of TBZ $(p>0.05)$. For $V$. mali, 10 of the compounds were equally or more active (53.3 82.3\%) than $\mathbf{C H}(57.1 \%)$ and 15 of the compounds were equally or more active (61.2-82.3\%) than SA $(69.1 \%)(p>0.05) . \mathbf{1 8}\left(\mathrm{R}=p-\mathrm{NO}_{2}\right)$ revealed the highest activity $(82.3 \%)$, equal to that of TBZ (86.0\%) $(p>0.05)$.

As to $F$. oxysporum sp. niveum, 10 of the 24 compounds were equally or more active (48.4-91.7\%) than SA (50.5\%) while seven of the compounds were equally or more active than $\mathbf{C H}(63.2 \%)$ $(p>0.05)$. For $F$. oxysporum $\mathrm{f}$. sp. vasinfectum, five of the compounds were equally or more active than SA (59.7\%) while nine of the compounds were equally or more active (48.2-74.6\%) than $\mathbf{C H}$ (47.6\%). In both cases mentioned above, 8 revealed the highest activities $(91.7 \%, 74.6 \%)$, but the activities of all the compounds were weaker than that of TBZ (100.0\%).

\subsection{Structure-Activity Relationship}

Qualitative structure-activity relationship was established by comparison of both the activities and structures of various test compounds 1-24. By comparison of the activity of $\mathbf{1}(\mathrm{R}=\mathrm{H})$ with that of the other compounds (2-24) on each the fungus (Table 1), it was clearly seen that the introduction of various substituents to $\mathrm{N}$-aromatic ring had significant effects on the activity, indicating that the $N$-phenyl group was a high sensitive structural moiety for the activity. The general trend was that electron-withdrawing substituents like halogen atoms $(\mathbf{2}-\mathbf{1 2})$, trifluoromethyl groups $\left(-\mathrm{CF}_{3}\right)(\mathbf{1 3}-\mathbf{1 5})$ and nitro groups $\left(m\right.$ - and $\left.p-\mathrm{NO}_{2}\right)(\mathbf{1 7}, \mathbf{1 8})$, especially halogen atoms, remarkably enhanced the activity. On the contrary, the presence of electron-donating groups like $-\mathrm{CH}_{3}(\mathbf{1 9}-\mathbf{2 1}), o-\mathrm{OH}(\mathbf{2 2})$, and $p-\mathrm{OCH}_{3}$ (24) led to a decrease of the activity in most cases (Figure 2).

Figure 2. Structure-activity relationship of the compounds 1-24.

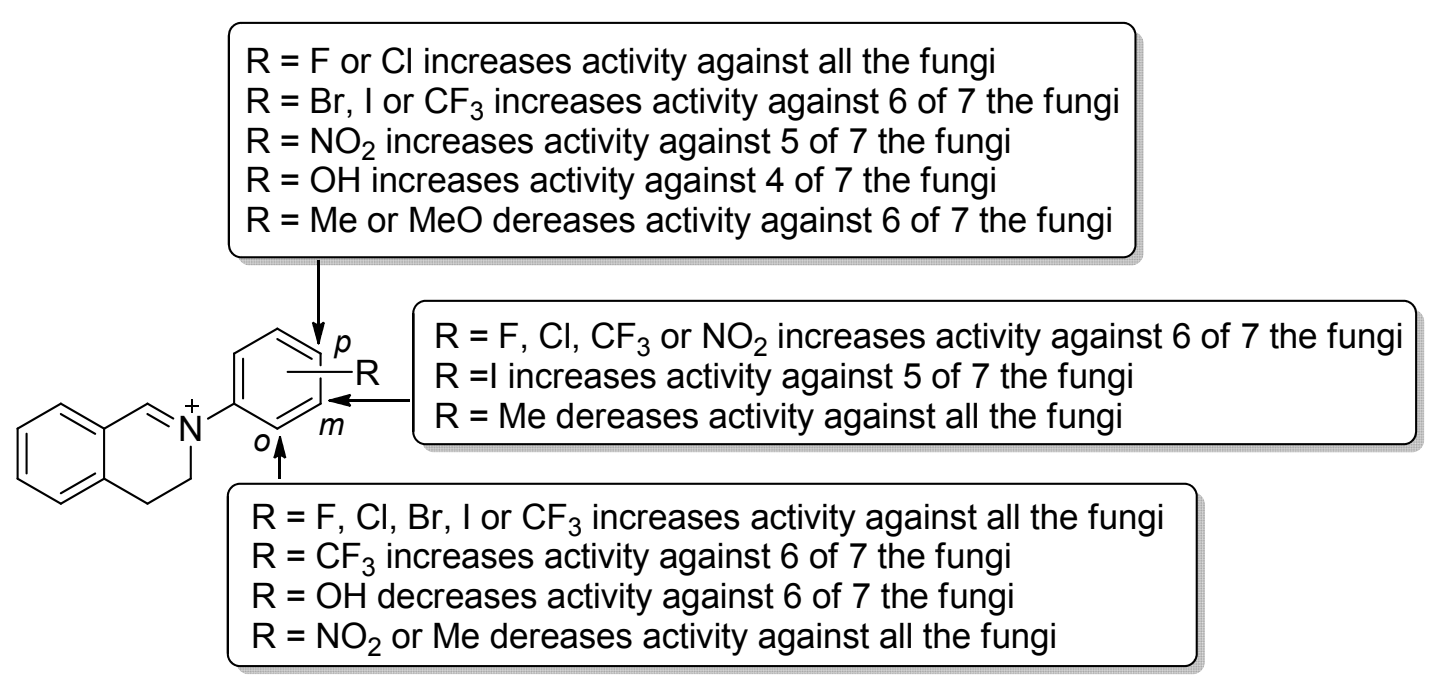


On the other hand, by comparison of the activity of various isomers on each the fungus, a significant effect of the position of the substituents on the activity was observed. For halogenated isomers (2-12), the order of position effect of the substituents $(-\mathrm{F},-\mathrm{Br},-\mathrm{Cl},-\mathrm{I})$ was $o$-substituted isomer $>p$-substituted isomer $>m$-substituted isomer in most cases. For example, for the three fluorinated compounds $\mathbf{2}-\mathbf{4}$, the $o$-F isomer $\mathbf{2}$ showed the strongest activity against each the test fungi, the $p$-F isomer $\mathbf{4}$ was the second, except for $C$. lunata, and the $m$-F isomer $\mathbf{3}$ gave the weakest activity except for C. lunata. A similar trend was also observed for chlorinated, brominated and iodinated isomers 5-12. The case for trifluoromethyl-substituted isomers was similar, but not identical to that of halogen atoms. Like the halogenated isomers $2-12$, the $o-\mathrm{CF}_{3}$ isomer 13 also gave the stronger activity on most of the fungi (6/7) than the $m-\mathrm{CF}_{3}$ isomer 14 and $p-\mathrm{CF}_{3}$ isomer 15 , but the activities of 14 and 15 showed no significant difference for all tested fungi except for $V$. mali $(p>0.05)$. The results above showed that for halogen atoms and trifluoromethyl group, the 2-site of the $N$-phenyl ring was beneficial for the improvement of the activity. Unlike the cases of halogen atoms and $-\mathrm{CF}_{3}$ group, an $o$-nitro group (compound 16) caused an obvious decrease of the activity for all the fungi while a $m$-nitro group (compound 17) and $p$-nitro group (compound 18) led to an enhancement of the activity. Among them, the $m$-nitro-substituted isomer 17 showed the best activity on 6 of 7 the fungi.

The results above indicate that the activity of the target compounds greatly depended on the characteristic and position of substituents on the $N$-aromatic ring. Generally, the introduction of F, $\mathrm{Cl}$ or $\mathrm{Br}$ to the I site in the $N$-phenyl ring resulted in a very great improvement of the activity.

\subsection{Antifungal Toxicity}

In order to more fully understand the antifungal activities of the compounds, the most active compounds 2, 4, 5, 7 and 8 were further evaluated as representative compounds for antifungal toxicity on seven phytophathogenic fungi.

Table 2. Toxicity regression equations and $\mathrm{EC}_{50}$ values of $\mathbf{2 , 4}, \mathbf{5}, 7$ and 8 against 7 fungi.

\begin{tabular}{|c|c|c|c|c|c|c|}
\hline \multirow{2}{*}{ Fungus } & \multirow{2}{*}{ Compd. } & \multirow{2}{*}{$\begin{array}{c}\text { Toxicity regression } \\
\text { equation * }\end{array}$} & \multirow{2}{*}{$R^{2}$} & \multicolumn{2}{|c|}{$\mathbf{E C}_{50}$} & \multirow{2}{*}{$95 \% \mathrm{CI} * *$ of $\mathrm{EC}_{50}$} \\
\hline & & & & $(\mu \mathrm{g} / \mathrm{mL})$ & $(\mu \mathrm{mol} / \mathrm{L})$ & \\
\hline \multirow[t]{7}{*}{ F.O.V. } & $2(o-\mathrm{F})$ & $y=1.4300 x+3.0769$ & 0.9780 & 22.12 & 72.2 & $20.74-23.60$ \\
\hline & $4(p-\mathrm{F})$ & $y=2.6168 x+0.4853$ & 0.9381 & 53.12 & 173.5 & $42.10-67.02$ \\
\hline & $5(o-\mathrm{Cl})$ & $y=1.2450 x+3.0099$ & 0.9433 & 39.67 & 123.0 & $36.31-72.17$ \\
\hline & $7(p-\mathrm{Cl})$ & $y=2.3044 x+1.3235$ & 0.9971 & 39.39 & 122.1 & $39.29-40.05$ \\
\hline & $8(o-\mathrm{Br})$ & $y=1.0996 x+3.7981$ & 0.9958 & 12.39 & 33.8 & $12.09-12.70$ \\
\hline & SA & $y=1.6623 x+2.4605$ & 0.9730 & 33.71 & 73.4 & $23.26-48.85$ \\
\hline & $\mathbf{C H}$ & $y=3.0902 x-0.3177$ & 0.9737 & 52.58 & 110.6 & $29.43-93.95$ \\
\hline \multirow[t]{7}{*}{ F.O.N. } & $2(o-\mathrm{F})$ & $y=2.4275 x+1.3864$ & 0.9769 & 30.80 & 100.6 & $29.98-31.64$ \\
\hline & $4(p-\mathrm{F})$ & $y=2.4139 x+1.5676$ & 0.9669 & 26.42 & 86.3 & $25.36-27.52$ \\
\hline & $5(o-\mathrm{Cl})$ & $y=1.3796 x+3.2094$ & 0.9373 & 19.86 & 61.6 & $18.05-37.91$ \\
\hline & $7(p-\mathrm{Cl})$ & $y=2.7227 x+0.9408$ & 0.9988 & 30.97 & 96.0 & $30.88-31.06$ \\
\hline & $8(o-\mathrm{Br})$ & $y=1.8107 x+3.1516$ & 0.9414 & 10.49 & 28.6 & $7.48-14.71$ \\
\hline & SA & $y=1.4175 x+2.5893$ & 0.9853 & 50.20 & 109.3 & $43.44-58.01$ \\
\hline & $\mathbf{C H}$ & $y=1.7052 x+2.5090$ & 0.9864 & 28.89 & 60.8 & $23.77-35.12$ \\
\hline
\end{tabular}


Table 2. Cont.

\begin{tabular}{|c|c|c|c|c|c|c|}
\hline \multirow{2}{*}{ Fungus } & \multirow{2}{*}{ Compd. } & \multirow{2}{*}{$\begin{array}{c}\text { Toxicity regression } \\
\text { equation * }\end{array}$} & \multirow{2}{*}{$R^{2}$} & \multicolumn{2}{|c|}{$\mathbf{E C}_{50}$} & \multirow{2}{*}{$95 \%$ CI $* *$ of $\mathrm{EC}_{50}$} \\
\hline & & & & $(\mu \mathrm{g} / \mathrm{mL})$ & $(\mu \mathrm{mol} / \mathrm{L})$ & \\
\hline \multirow[t]{7}{*}{ V.M. } & $2(o-F)$ & $y=2.3031 x+1.8962$ & 0.9836 & 22.27 & 72.7 & $21.71-26.42$ \\
\hline & $4(p-\mathrm{F})$ & $y=2.3521 x+1.3300$ & 0.9162 & 36.33 & 118.7 & $33.79-59.37$ \\
\hline & $5(o-\mathrm{Cl})$ & $y=2.0946 x+2.0847$ & 0.9651 & 24.65 & 76.4 & $23.21-26.18$ \\
\hline & $7(p-\mathrm{Cl})$ & $y=1.4730 x+2.9048$ & 0.9749 & 26.45 & 82.0 & $25.87-30.72$ \\
\hline & $8(o-\mathrm{Br})$ & $y=1.1731 x+3.4768$ & 0.9575 & 19.88 & 54.2 & $16.03-24.66$ \\
\hline & SA & $y=1.9432 x+2.2639$ & 0.9880 & 25.59 & 55.7 & $17.19-38.09$ \\
\hline & $\mathbf{C H}$ & $y=1.9658 x+1.8575$ & 0.9541 & 39.68 & 83.5 & $16.17-97.36$ \\
\hline \multirow[t]{7}{*}{ F.S. } & $2(o-F)$ & $y=2.1583 x+2.0918$ & 0.9938 & 22.25 & 72.7 & $22.05-23.64$ \\
\hline & $4(p-\mathrm{F})$ & $y=1.2769 x+3.4716$ & 0.9846 & 15.74 & 51.4 & $15.52-17.30$ \\
\hline & $5(o-\mathrm{Cl})$ & $y=1.0950 x+3.4884$ & 0.9583 & 24.02 & 74.5 & $22.95-32.70$ \\
\hline & $7(p-\mathrm{Cl})$ & $y=0.9805 x+3.5004$ & 0.9534 & 33.84 & 104.9 & $29.63-38.65$ \\
\hline & $8(o-\mathrm{Br})$ & $y=2.1420 x+2.9683$ & 0.9833 & 8.88 & 24.2 & $8.04-9.81$ \\
\hline & SA & $y=2.1928 x+1.4479$ & 0.9893 & 41.68 & 90.8 & $31.65-54.89$ \\
\hline & $\mathbf{C H}$ & $y=1.3614 x+3.0620$ & 0.9466 & 26.52 & 55.8 & $15.92-44.19$ \\
\hline \multirow[t]{7}{*}{ A.A. } & $2(o-F)$ & $y=1.3559 x+3.2997$ & 0.9835 & 17.95 & 58.6 & $17.50-21.32$ \\
\hline & $4(p-\mathrm{F})$ & $y=2.6327 x+1.3957$ & 0.9876 & 23.39 & 76.4 & $22.96-26.56$ \\
\hline & $5(o-\mathrm{Cl})$ & $y=1.1348 x+3.5676$ & 0.9738 & 18.29 & 56.7 & $17.57-24.00$ \\
\hline & $7(p-\mathrm{Cl})$ & $y=1.3719 x+3.3852$ & 0.9813 & 15.03 & 46.6 & $14.60-18.29$ \\
\hline & $8(o-\mathrm{Br})$ & $y=1.1204 x+3.9040$ & 0.9953 & 9.51 & 25.9 & $9.25-9.78$ \\
\hline & SA & $y=2.2140 x+1.1814$ & 0.9550 & 53.03 & 115.5 & $28.22-99.67$ \\
\hline & $\mathbf{C H}$ & $y=2.6508 x+0.5078$ & 0.9586 & 49.51 & 104.2 & $21.52-113.92$ \\
\hline \multirow[t]{7}{*}{ C.L. } & $2(o-\mathrm{F})$ & $y=1.3293 x+3.6629$ & 0.9725 & 10.14 & 33.1 & $7.28-14.11$ \\
\hline & $4(p-\mathrm{F})$ & $y=1.0827 x+3.7694$ & 0.9198 & 13.70 & 44.7 & $12.10-31.73$ \\
\hline & $5(o-\mathrm{Cl})$ & $y=1.3088 x+3.7443$ & 0.9169 & 9.11 & 28.2 & $7.10-11.69$ \\
\hline & $7(p-\mathrm{Cl})$ & $y=1.4152 x+3.4244$ & 0.9675 & 12.98 & 40.2 & $12.33-18.34$ \\
\hline & $8(o-\mathrm{Br})$ & $y=1.7125 x+3.3707$ & 0.9373 & 8.94 & 24.4 & $6.38-12.53$ \\
\hline & SA & $y=1.5699 x+2.5652$ & 0.9621 & 35.55 & 77.4 & $23.37-54.07$ \\
\hline & CH & $y=0.9154 x+3.9048$ & 0.9621 & 15.72 & 33.1 & $6.08-40.66$ \\
\hline \multirow[t]{7}{*}{ P.O. } & $2(o-\mathrm{F})$ & $y=1.0351 x+3.7446$ & 0.9531 & 16.33 & 53.3 & $15.63-21.97$ \\
\hline & $4(p-\mathrm{F})$ & $y=1.4434 x+2.8066$ & 0.9892 & 33.08 & 108.0 & $32.78-35.15$ \\
\hline & $5(o-\mathrm{Cl})$ & $y=0.8119 x+3.9161$ & 0.9818 & 21.63 & 67.0 & $20.66-22.82$ \\
\hline & $7(p-\mathrm{Cl})$ & $y=1.6338 x+2.6110$ & 0.9893 & 28.99 & 89.9 & $28.73-30.81$ \\
\hline & $8(o-\mathrm{Br})$ & $y=1.4194 x+3.4358$ & 0.9806 & 12.65 & 34.46 & $11.15-14.35$ \\
\hline & SA & $y=0.8326 x+3.3309$ & 0.9754 & 101.09 & 220.1 & $72.61-140.73$ \\
\hline & $\mathbf{C H}$ & $y=1.6792 x+2.1968$ & 0.9629 & 46.71 & 98.3 & $39.01-55.93$ \\
\hline
\end{tabular}

* $y$ : The probability of the inhibition rate; $x: \log [\operatorname{concentration}(\mu \mathrm{g} / \mathrm{mL})]$. ** 95\% CI: Lower and upper values of the confidence interval of $\mathrm{EC}_{50}(\mu \mathrm{g} / \mathrm{mL})$ at $95 \%$ probability.

Meanwhile, both SA and $\mathbf{C H}$ were used as positive controls. Based on the mycelial growth inhibitory rates of the compounds at a series of concentrations, toxicity regression equations of the compounds were established between $\log$ [concentration] value and probit value of inhibition rates by using the least square method. $\mathrm{EC}_{50}$ (median effective concentration) values of the compounds and 
their confidence intervals at $95 \%$ probability were calculated from the corresponding toxicity regression equations. The results are listed in Table 2.

All the tested compounds showed significant concentration-dependent antifungal activity toward every one of the tested fungi $\left(R^{2}\right.$ values $\left.=0.9162-0.9988\right)$ (Table 2$)$ and their $\mathrm{EC}_{50}$ values were in a range of 8.88 to $53.12 \mu \mathrm{g} / \mathrm{mL}$. From Table 2, it was clearly seen that most of the $\mathrm{EC}_{50}$ values $(27 / 35)$ of the tested compounds were lower than $30 \mu \mathrm{g} / \mathrm{mL}$. By contrast, most of $\mathrm{EC}_{50}$ values $(10 / 14)$ of SA and $\mathbf{C H}$ were greater than $30 \mu \mathrm{g} / \mathrm{mL}$. Among the tested compounds, 8 possessed the strongest activity on each the fungi and most of its $\mathrm{EC}_{50}$ values (6/7) were lower than $15 \mu \mathrm{g} / \mathrm{mL}$. Therefore, as far as the $\mathrm{EC}_{50}$ values were concerned, 2, 4, 5, 7 and $\mathbf{8}$ possessed stronger activity than $\mathbf{S A}$ and $\mathbf{C H}$ in most cases. In addition, It was worth mentioning that all the test compounds showed the highest activity on C. lunata $\left(\mathrm{EC}_{50}=8.94-13.7 \mu \mathrm{g} / \mathrm{mL}\right)$ among the seven fungi.

A slope value $(k)$ in a toxicity regression equation reflects concentration effect of a compound on its bioactivity. A greater $\mathrm{k}$ value implies that the antifungal activity of a test compound is more susceptible to its concentration change. The results in Table 2 showed that the $k$ values of each the test compound on various fungi or the $k$ values of various compounds on the same fungus were different, indicating that both the concentration effect of each the compound on the various fungi and the concentration effect of the various compounds on the same fungus were different.

A compound with better bioactivity should have a greater slope value and a smaller $\mathrm{EC}_{50}$ value at the same time. The ratio value of $k / \mathrm{EC}_{50}$ of a compound reflects its comprehensive activity (CA) to certain degree. In order to conveniently compare the CAs of the various compounds, we calculated the ratio of $\mathrm{CA}$ of each the compound to that of $\mathbf{C H}$ for the same fungus, i.e., relative comprehensive activity (RCA). As shown in Figure 3, 30 of 35 the RCA values of the five test compounds were greater than 1.0, i.e., the RCA value of $\mathbf{C H}$. This result indicated that all the tested compounds possessed stronger RCA than $\mathbf{C H}$ in most cases, in agreement with the data obtained from $\mathrm{EC}_{50}$ values in Table 2. In particular, both $\mathbf{2}$ and $\mathbf{8}(\mathrm{RCA}=1.10-4.70)$ showed higher activity than $\mathbf{C H}$ against all the tested fungi. Among the tested compounds, $\mathbf{2}$ showed the strongest activity against $V$. mail while $\mathbf{8}$ showed the strongest activity against the other fungi.

Figure 3. Relative comprehensive activities of the compounds against seven fungi.

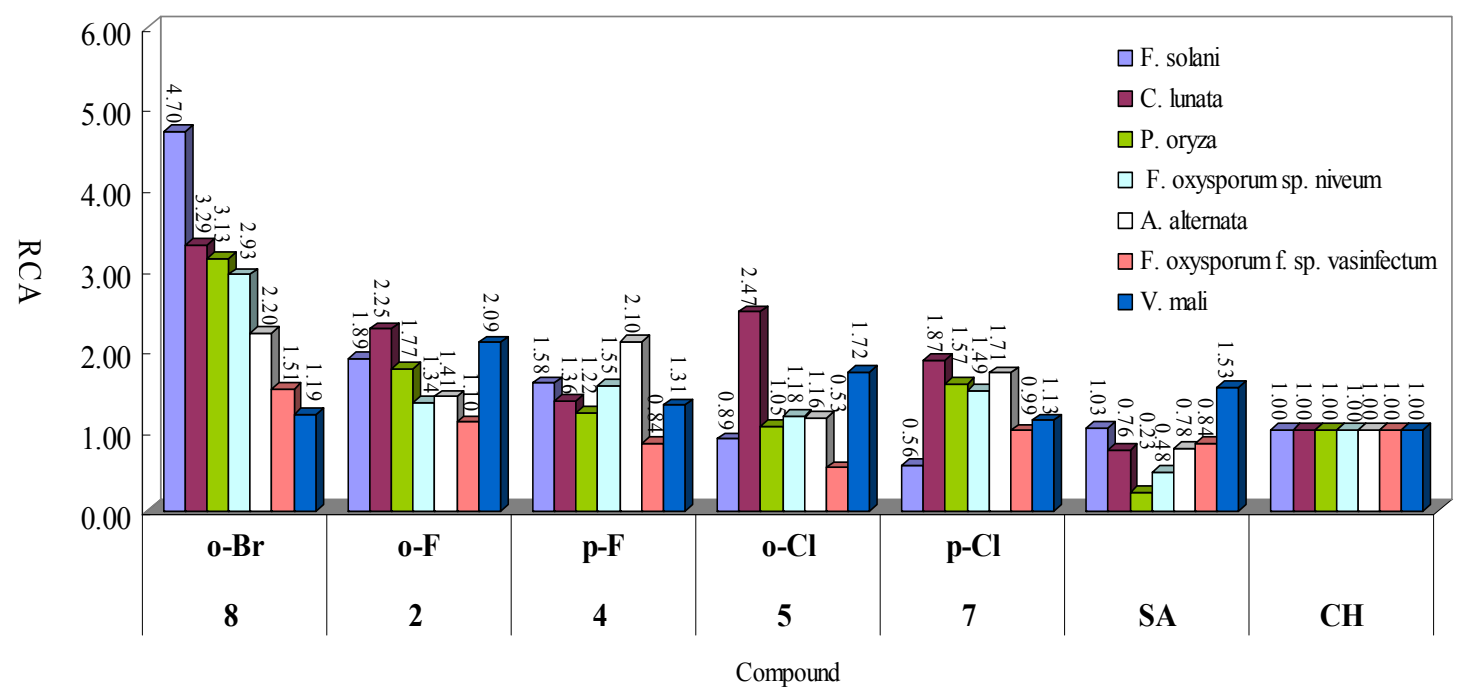




\section{Experimental}

\subsection{General}

Compounds 1-24 were obtained by synthesis according to our previously reported methods and their structures were determined by spectroscopic analysis [21]. Sanguinarine iodide (SA, >98\%) and chelerythrine iodide $(\mathbf{C H},>99 \%)$ were obtained in our laboratory by isolation from the whole plant of M. microcarpa (Maxim) Fedde [12]. Thiabendazole (TBZ, $\geq 99.1 \%$ ), a commercial fungicide standard, was purchased from Sigma-Aldrich Trading Co. Ltd. (Shanghai, China). Dimethyl sulfoxide (DMSO) was purchased from J\&K Chemical Ltd. (Beijing, China). Other reagents were obtained locally and of analytical grade. The water used was redistilled and ion-free.

Test fungi Fusarium oxysporum sp. vasinfectum, Fusarium oxysporum sp. niveum, Valsa mali, Fusarium solani, Alternaria alternate, Curvularia lunata and Pyricularia oryzae were isolated, identified and provided by the Center of Pesticide Research, Northwest A\&F University, Yangling, China. These fungi were grown on potato-dextrose-agar (PDA) plates at $28{ }^{\circ} \mathrm{C}$ and maintained at $4{ }^{\circ} \mathrm{C}$ by periodic subculturing.

\subsection{Assay of Antifungal Activity in Vitro}

The antifungal activity in vitro was assayed by the growth rate method reported by us [19]. The test fungi maintained on PDA medium slants were subcultured for $48 \mathrm{~h}$ in Petri dishes prior to testing and used for inoculation of fungal strains on PDA plates. The tested compounds were completely dissolved in DMSO, and then diluted by water to provide a stock solution $(1.2 \mathrm{mg} / \mathrm{mL})$ in $5 \%$ DMSO aqueous solution. Thiabendazole solution $(1.2 \mu \mathrm{g} / \mathrm{mL})$ in $5 \%$ DMSO aqueous solution and $5 \%$ DMSO aqueous solution were used as positive drug control and blank control, respectively. SA and $\mathbf{C H}$ solutions $(1.2 \mu \mathrm{g} / \mathrm{mL})$ in $5 \%$ DMSO aqueous solution were used as the model compound controls at the same time. The stock solution $(10 \mathrm{~mL})$ was completely mixed with the autoclaved PDA medium $(230 \mathrm{~mL})$ to provide a medium containing $50 \mu \mathrm{g} / \mathrm{mL}$ of test compounds and then poured into the Petri dishes in a laminar flow chamber. When the medium in the plate was partially solidified, a 5-mm thick and 4-mm diameter disc of fungus cut from earlier subcultured Petri dishes was placed at the centre of the semi-solid medium. The dishes were kept in an incubator at $28{ }^{\circ} \mathrm{C}$ for $72 \mathrm{~h}$. Each experiment was carried out in triplicate. The diameters (in $\mathrm{mm}$ ) of inhibition zones were measured in three different directions and the growth inhibition rates were calculated according to the following formula and expressed as means \pm S.D.:

$$
\text { Growth inhibition rate }(\%)=\left[\left(d_{\mathrm{c}}-d_{0}\right)-\left(d_{\mathrm{s}}-d_{0}\right)\right] /\left(d_{\mathrm{c}}-d_{0}\right) \times 100
$$

where $d_{0}$ : Diameter of the fungus cut, $d_{\mathrm{c}}$ : Diameter of the blank control fungus, $d_{\mathrm{s}}$ : Diameter of the compound-treated fungus.

Based on the in vitro antifungal activity screening results, the more active compounds 2, 4, 5, 7 and 8 were selected to determine their antifungal toxicity according to the method described above [19]. A stock solution of the compounds was prepared in 5\% DMSO aqueous solution, and then diluted by 5\% DMSO in water using serial two-fold dilution method to obtain a series of stock solutions. Each stock solution $(10 \mathrm{~mL})$ was respectively mixed with the autoclaved PDA medium to prepare a set of media 
containing 120, 90, 80, 40, 20, 10, 5 and $2.5 \mu \mathrm{g} / \mathrm{mL}$ compounds. Meanwhile, 5\% DMSO aqueous solution was used as blank control. The antifungal activity for each concentration of the compounds was determined. Each experiment was performed in triplicate. The average inhibition rate for each test was calculated and then transformed to the corresponding probit value. The concentration of the compound was transformed to the corresponding logarithm value $\left(\log _{10} C\right)$. $\log _{10} C$ values for each compound and its corresponding probit values were used to establish toxicity regression equation by using the least square method. $\mathrm{EC}_{50}$ values and their confidence interval at $95 \%$ probability were calculated from the toxicity regression equations. RCA of each compound was calculated according to the following formula:

$$
\begin{gathered}
\mathrm{RCA}=(\text { slope value of the test compound/slope value of } \mathbf{C H}) \times \\
\left(\mathrm{EC}_{50} \text { value of } \mathbf{C H} / \mathrm{EC}_{50} \text { value of the test compound }\right)
\end{gathered}
$$

\subsection{Statistic Analysis}

SPSS V17.0 statistical software was used to analyze the data and establish toxicity regression equations. Duncan multiple comparison test was performed on the data to determine significant difference between the inhibition rates of various compounds at the same concentration.

\section{Conclusions}

2-Aryl-3,4-dihydroisoquinolin-2-ium bromides are a class of structurally simple QBA-like compounds. In the present study, we evaluated in vitro antifungal activities of a series of synthesized 2-aryl-3,4-dihydroisoquinolin-2-ium bromides with various substituents on the $N$-aromatic ring against seven pathogenic fungi and discussed their structure-activity relationships as well as compared their activities with that of their natural model compounds SA and $\mathbf{C H}$. Like SA and $\mathbf{C H}$, almost all the compounds 1-24 displayed the activities against all the fungi in varying degrees at $50 \mu \mathrm{g} / \mathrm{mL}$ and a broad antifungal spectrum. The $N$-phenyl ring was proven to be a highly influential structural moiety for the activity. The introduction of substituents to $\mathrm{N}$-phenyl ring led to significant change of the activity. Generally, electron-withdrawing substituents such as $-\mathrm{X}\left(\mathrm{X}=\mathrm{F}, \mathrm{Cl}, \mathrm{Br}\right.$ or I), $-\mathrm{CF}_{3}$ and $-\mathrm{NO}_{2}$, especially $-\mathrm{X}$, remarkably enhanced the activity. On the contrary, electron-donating groups such as $-\mathrm{CH}_{3}, o-\mathrm{OH}$, and $p-\mathrm{OCH}_{3}$ result in the decrease of the activity in most cases. In addition, the position of substituents was able to significantly influence the activity also. For halogenated compounds, the order of the activity of various isomers was generally $o$-substituted isomer $>p$-substituted isomer $>$ $m$-substituted isomer. In most cases, most of the halogenated compounds $\mathbf{2} \sim \mathbf{1 2}$ showed higher activity than SA and CH. 2, 4, 5, 7 and 8 showed significant concentration-dependent antifungal activity toward the tested fungi. Both $\mathbf{2}$ and $\mathbf{8}$, especially $\mathbf{8}$, showed higher RCAs than SA and $\mathbf{C H}$ against all the 7 tested fungi. Thus, 2-aryl-3,4-dihydroisoquinolin-2-ium compounds might be considered as promising lead compounds for the development of novel isoquinoline antifungal agrochemicals. Compounds $\mathbf{2}, \mathbf{4}, \mathbf{5}, \mathbf{7}$ and $\mathbf{8}$, and especially $\mathbf{2}$ and $\mathbf{8}$, are of great potential as new antifungal agents for plant protection.

Compared with the natural model compounds SA or $\mathbf{C H}$, the title compounds had some obvious advantages such as more simple structure, higher bioactivity, higher high atom economy, easy 
chemical synthesis on a large scale and lower cost, etc. In addition, our recent research had demonstrated that the title compounds were safe for plant growth (unpublished data). Therefore, the title compounds should have broad application prospects in agriculture as novel biomimetic fungicides and alternatives to the natural model compounds.

\section{Acknowledgments}

This project was financially supported by the National Natural Science Foundation of China (NNSF; No. 31000865, 31172365, 31101469).

\section{Conflicts of Interest}

The authors declare no conflict of interest.

\section{References}

1. Savary, S.; Teng, P.S.; Willocquet, L.; Nutter, F.W., Jr. Quantification and modeling of crop losses: A review of purposes. Annu. Rev. Phytopathol. 2006, 44, 89-112.

2. Bräse, S.; Encinas, A.; Keck, J.; Nising, C.F. Chemistry and biology of mycotoxins and related fungal metabolites. Chem. Rev. 2009, 109, 3903-3990.

3. Bai, Y.B.; Zhang, A.L.; Tang, J.J.; Gao, J.J. Synthesis and antifungal activity of 2-chloromethyl1H-benzimidazole derivatives against phytopathogenic fungi in vitro. J. Agric. Food Chem. 2013, 61, 2789-2795.

4. Wedge, D.E.; Camper, N.D. Biologically active natural products. In Agrochemicals and Pharmaceuticals; Cutler H.G., Cutler S.J., Eds.; CRC Press: Boca Raton, FL, USA, 2000; pp. 1-15.

5. Dostál, J; Slavík, J. Some aspects of the chemistry of quaternary benzo[c]phenanthridine alkaloids. In Studies in Natural Products Chemistry, 1st ed.; Atta-ur-Rahman, Ed.; Elsevier Scicence B.V: Oxford, UK, 2002; Volume 27, Part H, pp. 155-184.

6. Miao, F.; Yang, X.J.; Ma, Y.N.; Zheng, F.; Song, X.P.; Zhou, L. Structural modification of sanguinarine and chelerythrine and their in vitro acaricidal activity against Psoroptes cuniculi. Chem. Pharm. Bull. 2012, 60, 1508-1513.

7. Lenfeld, J.; Kroutil, M.; Maršálek, E.; Slavík, J.; Preininger, V.; Šimánek, V. Antiinflammatory activity of quaternary benzophenanthridine alkaloids from Chelidonium majus. Planta Med. 1981, 43, 161-165.

8. Psotova, J.; Vecera, R.; Zdarilova, A.; Anzenbacherova, E.; Kosina, P.; Svobodova, A.; Hrbac, J.; Jirovsky, D.; Stiborova, M.; Lichnovsky, V.; et al. Safety assessment of sanguiritrin, Alkaloid fraction of Macleaya cordata, in rats. Vet. Med. 2006, 51, 145-155.

9. Kosina, P.; Walterova, D.; Ulrichova, J.; Lichnovsky, V.; Stiborova, M.; Rydlova, H.; Vicar, J.; Krecman, V.; Brabec, M.J.; Simanek, V. Sanguinarine and chelerythrine: Assessment of safety on pigs in ninety days feeding experiment. Food Chem. Toxicol. 2004, 42, 85-91.

10. Ahsan, H.; Reagan-Shaw, S.; Breur, J.; Ahmad, N. Sanguinarine induces apoptosis of human pancreatic carcinoma AsPC-1 and BxPC-3 cells via modulations in Bcl-2 family proteins. Cancer Lett. 2007, 249, 198-208. 
11. Meng, F.Y.; Zuo, G.Y.; Hao, X.Y.; Wang, G.C.; Xiao, H.T.; Zhang, J.Q.; Xu, G.L. Antifungal activity of the benzo[c]phenanthridine alkaloids from Chelidonium majus Linn against resistant clinical yeast isolates. J. Ethnopharmacol. 2009, 125, 494-496.

12. Miao, F.; Yang, X.J.; Zhou, L.; Hu, H.J.; Zheng, F.; Ding, X.D.; Sun, D.M.; Zhou, C.D.; Sun W. Structural modification of sanguinarine and chelerythrine and their antibacterial activity. Nat. Prod. Res. 2011, 25, 863-875.

13. Kerry, M.A.; Duval, O.; Waigh, R.D.; Mackay, S.P. The role of the iminium bond in the inhibition of reverse transcriptase by quaternary benzophenanthridines. J. Pharm. Pharmacol. 1998, 50, 1307-1315.

14. Eun, J.P.; Koh, G.Y. Suppression of angiogenesis by the plant alkaloid, Sanguinarine. Biochem. Biophys. Res. Commun. 2004, 317, 618-624.

15. Cho, K.M.; Yoo, I.D.; Kim, W.G. 8-Hydroxydihydrochelerythrine and 8-hydroxydihydrosanguinarine with a potent acetylcholinesterase inhibitory activity from Chelidonium majus L. Biol. Pharm. Bull. 2006, 29, 2317-2320.

16. Yao, J.Y.; Li, X.L.; Shen, J.-Y.; Pan, X.Y.; Hao, G.J.; Xu, Y.; Ying, W.L.; Ru, H.S.; Liu, X.L. Isolation of bioactive components from Chelidonium majus L. with activity against Trichodina $\mathrm{sp}$. Aquaculture 2011, 318, 235-238.

17. Wang, G.X.; Zhou, Z.; Jiang, D.X.; Han, J.; Wang, J.F.; Zhao, L.W.; Li, J. In vivo anthelmintic activity of five alkaloids from Macleaya microcarpa (Maxim) Fedde against Dactylogyrus intermedius in Carassius auratus. Vet. Parasitol. 2010, 171, 305-313.

18. Nyangulu, J.M.; Hargreaves, S.L.; Sharples, S.L.; Mackay, S.P.; Waigh, R.D.; Duval, O.; Mberu, E.K.; Watkins, W.M. Antimalarial benzo[c]phenanthridines. Bioorg. Med. Chem. Lett. 2005, 15, 2007-2010.

19. Yang, X.J.; Miao, M.; Yao, Y.; Cao, F.J.; Yang, R.; Ma, Y.N.; Qin, B.F.; Zhou L. In vitro antifungal activity of sanguinarine and chelerythrine derivatives against phytopathogenic fungi. Molecules 2012, 17, 13026-13035.

20. Nakanishi, T.; Suzuki, M.; Saimoto, A.; Kabasawa, T.J. Structural considerations of NK109, An antitumor benzo[c]phenanthridine alkaloid. J. Nat. Prod. 1999, 62, 864-867.

21. Ma, Y.N.; Yang, X.J.; Pan, L.; Hou, Z.; Geng, H.L.; Song, X.P.; Zhou, L.; Miao, F. Synthesis of 2-aryl-3,4-dihydroisoquinolin-2-ium bromides and their in vitro acaricidal activity against Psoroptes cuniculi. Chem. Pharm. Bull. 2013, 61, 204-211.

Sample Availability: Samples of the compounds 1-24 are available from the authors.

(C) 2013 by the authors; licensee MDPI, Basel, Switzerland. This article is an open access article distributed under the terms and conditions of the Creative Commons Attribution license (http://creativecommons.org/licenses/by/3.0/). 